REVISTA CHILENA DE LITERATURA

Noviembre 2009, Número 75, 295 - 306

\title{
EL SENTIMIENTO DE NO ESTAR DEL TODO: EL DISCURSO IDENTITARIO LATINOAMERICANO EN DOS CUENTOS DE JULIO CORTÁZAR
}

\author{
Olga Ostria Reinoso \\ Universidad del Bío Bío \\ eostria@ubiobio.cl
}

Nos proponemos leer dos relatos de Julio Cortázar ("Lejana" y "El otro cielo") como expresión y propuesta de un discurso identitario latinoamericano. Entendemos que se trata de una búsqueda personal, de un camino trazado por la propia experiencia, contextualizada por la cultura del Río de la Plata y por los avatares históricos que enmarcaron su existencia, en un diálogo continuo y fluido con un complejo archisistema de textos literarios, artísticos y culturales. En tal dirección, su escritura manifestaría una de las posibles caras de América Latina: su devenir escindido, su unidad no resuelta, su condición "heterogénea no dialéctica", según la expresión acuñada por Antonio Cornejo Polar. Se asume, pues, una interpretación de la historia latinoamericana que la entiende como proceso caracterizado por múltiples choques culturales y sociales, por la dominación de unas culturas sobre otras $-\mathrm{y}$, consecuentemente, de unas clases sobre otras-, de lo que resulta una convivencia nunca armoniosa, siempre disonante, de los elementos indígenas, africanos y europeos que en ella coexisten. Las huellas de esa historia preñada de conflictos permanecen en forma de mitos, de tradiciones, de discursos, que moldeados por la fortísima y en extremo conflictiva presencia "del otro" -tantas veces negada, silenciada, ocultada, reprimida-, sigue determinando la tónica de un devenir identitario traumático y complicado.

Se trata, entonces, de pensar la identidad latinoamericana no como una esencia que hay que desentrañar, ni como una sustancia dada de una vez y para siempre, sino como una categoría en proceso que se forma y rearticula en las intersecciones -móviles y provisorias- abiertas por cada sujeto entre lo dado y lo creado; no como modelos por alcanzar o repertorios fijos de atributos naturales, sino como juegos interpretativos que recurren a múltiples escenificaciones y teatralizaciones (Richards 345), como constructos discursivos y semióticos que permiten leer los procesos sociales. En suma, la identidad latinoamericana se nos aparece como una compleja red de solidaridades y vínculos textuales presentes en diversos relatos en los que, a la vez, nos reconocemos y nos diferenciamos. 
Por eso, los relatos identitarios que elabora Cortázar habremos de concebirlos como propuestas hacia la construcción de sentidos que, a su vez, posibiliten entender, desde múltiples perspectivas, el complejo devenir sociocultural de América Latina. En este contexto, nos parece que la literatura rioplatense en su vertiente fantástica también puede considerarse heterogénea, poseedora de ese doble estatuto sociocultural, en la medida en que surge de un proceso de transculturación que no se resuelve en un mestizaje desproblematizado y armonioso.

Es necesario precisar, sin embargo, que la heterogeneidad en la cultura del Río de la Plata tiene distinto signo que la correspondiente al universo andino, estudiada preferentemente por Cornejo Polar. El conflicto en la cultura rioplatense no se da entre lo indígena y lo criollo o mestizo, sino dentro del propio mundo criollo dividido entre el interior y la capital y casi siempre enajenado por un fuerte europeísmo. En efecto, "las generaciones que organizaron países como Argentina y Uruguay son parte, originalmente, del contexto latinoamericano; pero la falta de tradición indígena las hace caer en una excesiva admiración por la cultura europea" (Rodríguez Ozán 6). De ahí que sostenga Ernesto Sábato que la Argentina "es una fractura entre dos continentes: no somos ni Europa propiamente dicha, ni América Latina propiamente dicha” (Cit. en Arpini 210). Esto explicaría, al menos en parte, el surgimiento en la región de una denominada "tradición del destierro y el desarraigo". Esa fractura expresa, en verdad, una relación profundamente ambigua y problemática con lo propio y lo otro (a veces campesino, indígena, a veces inmigrante). Así entendido el funcionamiento de la heterogeneidad en la Cuenca del Plata, podemos acercarnos a una de sus expresiones literarias características, la literatura fantástica, específicamente el relato fantástico cortazariano.

Como en general los textos latinoamericanos, la escritura de Cortázar "pone en relación dos universos diferenciados y contradictorios [...], lo que implica enfrentarse a los conflictos propios del disloque de dos cosmovisiones con racionalidades no compatibles" (Cornejo, El problema 29), y expresa a su modo aquella compleja relación con la otredad que parece caracterizar a la cultura rioplatense ${ }^{1}$. Asimismo, los personajes, narradores y/o sujetos de la enunciación inscritos en sus textos (narrativa y ensayo) pueden estudiarse desde la categoría de sujeto transcultural, en términos de Fernando Ortiz, y la de sujeto heterogéneo, migrante ${ }^{2}$, del mismo Cornejo, pues igualmente se caracterizan por el

1 La problematización de la contraposición de planos que el relato fantástico de Cortázar pone en escena es la que, fundamentalmente, nos permite leer sus textos desde este punto de vista. Tal procedimiento, hay que precisar, no se desarrolla del mismo modo en toda literatura fantástica, ni siquiera, creemos, en todos los exponentes de su vertiente rioplatense. No obstante, son indiscutidos los vínculos poéticos entre la escritura cortazariana y dicha vertiente (Borges, Bioy Casares, Quiroga, Felisberto Hernández, Macedonio Fernández), de manera tal que requeriría estudiar detenidamente la obra de cada autor para constatar si es posible aplicar en todos los casos la categoría y reflexiones de Cornejo, de la forma que aquí lo hacemos.

2 “[...] hecho de la inestable quiebra e interacción de muchas identidades disímiles, oscilantes y heteróclitas" (Cornejo, Escribir en el aire 21). 
desarraigo y la memoria, por su instalación "en dos mundos de cierta manera antagónicos" (Cornejo, Escribir en el aire 213).

\section{"LEJANA": YO SOY OTRA}

En el cuento "Lejana", la escisión del yo aparece como problema de descomposición de la personalidad individual, de desdoblamiento del sujeto, pero también de irrupción de lo otro, presencia de lo desconocido en la propia conciencia. La historia trata básicamente de una joven porteña, de vida acomodada, llamada Alina Reyes, invadida mental y sentimentalmente por la presencia insólita de otra mujer, 'la lejana', y con ello, por vivencias radicalmente opuestas a las suyas (en concreto, una filiación social y espacial diferente), que terminan alienándola totalmente.

Como se nos anuncia en seguida del título, el texto representa el "Diario de Alina Reyes" y, por consiguiente, comienza siendo narrado en primera persona, con todo el intimismo, la naturalidad y la autenticidad que la forma del diario de vida conlleva. Consecuentemente, se trata de un texto autorreflexivo, en el sentido de que narradora y narrataria son la misma persona, el sujeto enunciante desdoblado. El diario asume la verosimilitud de ese tipo de discurso y, por consiguiente, el estilo introspectivo donde el yo dialoga consigo mismo a solas constituye una especie de garantía de fidelidad respecto de las ideas y sentires de su autora contenidos en el texto. El mismo registro nos hace partícipes de las profundidades del yo y de su angustiosa lucha por descifrar lo que ocurre en su conciencia; es, de alguna manera, el espejo en el que la protagonista se contempla y, en este sentido, es en sí mismo dador de identidad: el lenguaje empleado, el tono porteño, los rasgos citadinos y las actitudes burguesas, volcados en el diario, van así figurando la personalidad confusa de la protagonista, su identidad problemática. Huelga destacar, en tal dirección, la incorporación del habla coloquial de manera artística en el texto, cuya función es la búsqueda de una expresión literaria propia y viva, es decir, enraizada en una realidad concreta ${ }^{3}$. El reflejo ortográfico de la lengua oral urbana, llevado a cabo a través de creaciones idiomáticas individuales, juegos del lenguaje, variantes típicas del español en Argentina, entremezclados con los más variados registros, dan paso a una forma de escritura que es capaz de representar literariamente una manera peculiar de hablar y de pensar. Así, la yuxtaposición de hechos que se enumeran sin nexo aparente o bien las construcciones elípticas sugieren en ocasiones el divagar de la conciencia: "Pero sí, Alina Reyes, y por eso anoche fue otra vez, sentirla y el odio" (Cortázar, Lejana 119).

Los coloquialismos léxicos ("soy una chica sin humos"; "parapeto" 125), entre los que llama la atención una solitaria inclusión del característico "che" ("Eso le da frío a cualquiera, che, aquí o en Francia"125), además de los familiarismos, los diminutivos y aumentativos ("M'hijita, la última vez que te pido que me acompañes al piano. Hicimos

3 Véase: Bajtín, Estética. 
un papelón" 120; "enormísimo", “abrigadísimo"123, "delgadísima”, "lindísima” 125), entre otros rasgos gramaticales de la lengua conversacional, a todo lo cual debe sumarse el sintomático uso de fragmentos en lenguas extranjeras ("Votre âme est un paysage choisi..."120, "pink champagne", "Now I lay me down to sleep..." 119), van otorgando expresión a ese estilo oral coherente con la realidad idiomática argentina que Cortázar se esmera en recrear artísticamente; tarea que irá ampliando en sus escritos posteriores ${ }^{4}$. Estas estilizaciones orales contribuyen, asimismo, a elaborar un carácter que remite a la denominada "tradición del desarraigo" rioplatense y a su "europeísmo" característico, en la medida en que los personajes parecen expresarse cotidianamente mediante lenguas foráneas: la palabra propia asume así registros ajenos. La presencia de vocablos extranjeros sin traducir contribuye también a la configuración de un personaje en tránsito que pertenece a espacios simultáneos, pero distintos y distantes, no fundidos.

De igual modo, esas cualidades de la escritura nos permiten, en tanto lectores, ser testigos casi directos e inmediatos, intrusos de lo íntimo, del complejo proceso de disyunción de personalidad que Alina Reyes sufre por efecto de la irrupción de lo otro y, al mismo tiempo, de la difuminación del límite entre lo real y lo supuestamente imaginario. Sin embargo, convengamos en que no se trata de una división patológica de la personalidad, sino más bien de una expansión del ego, de una "participación", como diría Cortázar, simultánea de algo hasta entonces desconocido (elemento fantástico) que vuelve sospechosa la normalidad del yo, revelando la indeterminación de la propia identidad. Se trata de la irrupción de lo otro (la otra), lo aparentemente lejano y sin conexión que, sin embargo, de modo inexplicable se va apoderando hasta compartir la identidad escindida de la protagonista.

El anagrama incompleto con el que ella juega constituye la metáfora lingüística de aquella mencionada indefinición de la identidad: "Alina Reyes es la reina y...". Desde esa perspectiva, Alina es una especie de anagrama vivo en el que el espacio en blanco o los puntos suspensivos nos insinúan que es alguien más, que le falta algo para ser totalmente, algo que aún no ha descubierto, completamente opuesto a lo que ella sabe y cree de sí: se trata de un otro yo, de una otra realidad, que inicialmente provoca incomprensión y rechazo, y posteriormente incita a su búsqueda e integración.

Efectivamente, a partir de aquel juego del lenguaje se constata que 'la lejana' está elaborada en cuanto doble opuesto de Alina; todo en ella constituye la antítesis de la protagonista: 'la lejana' es pobre porque Alina tiene una vida holgada, vive en Budapest (la ciudad doble), porque Alina vive en Buenos Aires, al otro lado del océano, es maltratada por su pareja, porque Alina maltrata, se burla, de su propio novio -"Pobre Luis María, qué idiota casarse conmigo. No sabe lo que se echa encima" (123). Ambas conciencias se iluminan mutuamente, configurándose como el reflejo invertido de cada

$4 \mathrm{Al}$ respecto, el escritor ha señalado que "[...] es necesario encontrar un lenguaje literario que llegue por fin a tener la misma espontaneidad, el mismo derecho que nuestro hermoso, inteligente, rico y hasta deslumbrante estilo oral" (Cit. en Donni 71-83). 
una. La 'Alina miserable' no puede ser quien es sin la opulenta porteña, y viceversa. De ahí que se configuren en cuanto opuestos complementarios, relación en la que los límites de la ajenidad tienden a desvanecerse. No en vano la otredad se manifiesta en este relato mediante la experiencia de una presencia ajena como si fuera propia, de una voz extrínseca hablando desde dentro.

Pero, como dijimos, no se trata de que unas veces la protagonista es Alina Reyes y otras 'la lejana', sino de una coexistencia simultánea de esos dos yo. Es más bien un problema de perspectivas opuestas conviviendo en un mismo ser. La continua presencia ajena-lejana enfatiza en Alina el sentimiento de descolocación, de estar a medias, una incomodidad que no la deja ser feliz ni con una realidad ni con la otra.

Recapitulando, el proceso de conciencia que el diario narra, va mostrando cómo lo otro irrumpe progresivamente en el yo, cómo lo cotidiano es sobresaltado por lo insólito, en última instancia, cómo lo fantástico se va apoderando poco a poco de toda realidad razonable y cierta -destruyendo toda lógica y certidumbre-, así como de la conciencia y la personalidad de Alina, a pesar del intenso rechazo que ella manifiesta en un comienzo: la alteridad se revela y se niega a la vez. Se da así una lucha de personalidades, expresada estilísticamente por medio del uso intercalado de la primera y la tercera personas. El discurso ajeno se yuxtapone al propio, lo invade: "porque soy yo y le pegan"; "Porque a mí, a la lejana, no la quieren". Se va dando una especie de imposición del yo otro, europeo, que, por cierto, es el yo miserable y sufriente, -invirtiéndose los términos atribuidos tradicionalmente a las culturas europeas (rica) y latinoamericanas (pobre)-, con el cual no existe un diálogo, mas sí el deseo de comunicación, expresado en las ansias de Alina de enviarle un telegrama a la Lejana.

De forma homóloga, pero mucho más potente que el caso de las expresiones extranjeras enturbiando los discursos porteños, el decir propio aparece ahora saturado de tonalidades y sentidos ajenos, a tal punto que deforma la voz de Alina, la hace sonar de otra manera, volviéndola "turbulenta, irresoluble internamente y ambivalente" (Bajtin 289). He ahí la duplicidad contradictoria presente en la misma enunciación, en la forma de dos discursos que si bien no pueden actuar independientemente el uno del otro, tampoco se hallan fusionados de modo desproblematizado. En ese sentido es que "la palabra llega a ser arena de lucha entre dos voces" (Bajtin 289).

Parafraseando a Cornejo Polar, ocurre aquí que "sujeto y discurso se pluralizan agudamente y el cuento como tal se transforma en un espacio donde uno y otro pierden sus identidades seguras y definidas..." (Escribir en el aire 215). La protagonista deviene, en tal sentido, sujeto heterogéneo, plural y también sujeto transcultural, en el sentido de que en ella se da un proceso transitivo, de paso entre mundos.

Tal vez por ello es que a medida que el cuento y los días en el diario avanzan, el yo evoluciona hacia una posición de aceptación del otro e incluso de deseo de encuentro y de posesión. Aquí la figura del puente, tan propia de Cortázar, adquiere relevancia primordial. En efecto, a Alina le obsesiona la idea del puente; el término, propiamente tal, recorre el texto sin discreción alguna. "Más fácil salir a buscar ese puente, salir en busca mía y encontrarme como ahora, porque ya he andado la mitad del puente entre gritos y aplausos..." (Cortázar, Lejana 123). 
El puente simboliza claramente la posibilidad de paso, de cruce de umbral y, consecuentemente, de reunión e integración añorada por el ser escindido. Leemos también en esta metáfora ese anhelo de diálogo, de comunicación entre Europa y Buenos Aires. Lo otro, en este caso lo europeo, se presenta como una especie de dimensión inevitable de la realidad del yo bonaerense. Pareciera que éste no puede colmar su identidad sin ese otro complementario. Europa: síntoma de lo que el rioplatense no es, pero, al mismo tiempo, de lo que sí es. Juego confuso y a veces angustiante entre las imágenes del yo y del otro, del yo que no solo es incapaz de sacudirse del otro (de su discurso, de su mirada), sino que además se reconoce en él constantemente; y que hace visible, más extensamente, el sospechoso y paradójico sentimiento de que Latinoamérica es y no es Europa.

El anhelo de reunión, de fusión de la identidad quebrada de la protagonista - "Se doblegará si realmente soy yo, se sumará a mi zona iluminada, más bella y cierta con solo ir a su lado y apoyarle una mano en el hombro" (124)- no logra la concreción deseada. El diario termina el 7 de febrero y entonces se da paso a una voz en tercera persona, un narrador aparentemente omnisciente que otorga cierto halo de certeza a la historia y que relatará el esperado y al mismo tiempo sorprendente encuentro final, en medio del puente en Budapest.

Ceñía a la mujer delgadísima, sintiéndola entera y absoluta dentro de su abrazo, con un crecer de felicidad igual a un himno, a un soltarse de palomas, al río cantando. Cerró los ojos en la fusión total, rehuyendo las sensaciones de afuera, la luz crepuscular; repentinamente tan cansada, pero segura de su victoria, sin celebrarlo pero tan suyo y por fin (125).

El abrazo narrado como un instante supremo de unión parece tan solo un bluff del narrador, una especie de anticlímax -igualmente fantástico-, pues lo que ocurre parece ser un insólito traspaso de identidades. Los esfuerzos por conquistar lo otro son finalmente vanos. El anhelo de reconciliación de las dos orillas sigue ahí.

Al abrir los ojos (tal vez gritaba ya) vio que se habían separado. Ahora sí gritó. De frío, porque la nieve le estaba entrando por los zapatos rotos, porque yéndose camino de la plaza iba Alina Reyes lindísima en su sastre gris, el pelo un poco suelto contra el viento, sin dar vuelta la cara y yéndose (125).

Queda subrayar que el conflicto entre lo propio y lo ajeno, expresado en este cuento fantástico, ofrece múltiples opciones de lectura. Una de ellas apunta a la posibilidad de interpretar tal problemática desde el contexto latinoamericano, y en ese sentido, percibirla como una metáfora de la heterogénea realidad latinoamericana y en, consecuencia, como una manifestación de la identidad del continente en términos de fragmentación y pluralidad contradictoria. 


\section{"EL OTRO CIELO": LOS VASOS COMUNICANTES}

A partir de una narración atribuida a un personaje que vive simultáneamente en Buenos Aires (1928 y 1945) y París (1868), "El otro cielo" ofrece un nítido ejemplo de superposición espaciotemporal, llevada a cabo por Cortázar sin aclaración alguna, con toda naturalidad, tal como se presenta la irrupción de lo otro en toda la cuentística del autor; rasgo pertinente, por lo demás, de su concepción de lo fantástico.

Desde el título mismo del cuento se nos plantea el enigma de la alteridad y se nos advierte, en consecuencia, respecto de unas circunstancias narrativas evidentemente duales y disímiles: existe un cielo y el otro. Ambas zonas se hallan conectadas a través del protagonista y de las galerías por las que éste deambula: "Me ocurría a veces que todo se dejaba andar, se ablandaba y cedía terreno, aceptando sin resistencia que se pudiera ir así de una cosa a otra" (Cortázar, El otro cielo 590). No en vano el personaje principal es precisamente un corredor de la Bolsa. Él mismo se constituye en umbral hacia lo otro, en lugar donde confluyen las distintas esferas de realidad, al trasladarse del pasaje Güemes, en la capital argentina, a la Galería Vivienne, en la capital francesa del siglo XIX: "Mi paseo terminaba en el barrio de las galerías cubiertas, quizá porque los pasajes y las galerías han sido mi patria secreta desde siempre" (590, énfasis mío). Probablemente sea este fragmento el que ilustra de manera más explícita el vínculo entre la poética fantástica de Cortázar y el tema de la identificación nacional y continental, que se vincula con nuestra lectura de ella. Efectivamente, la idea de que los pasadizos son la patria profunda del personaje enfatiza esa capacidad porosa, camaleónica del ser humano, que le permite sumarse otras realidades y, en consecuencia, devenir otra cosa. Capacidad que nuestro autor se esmera en integrar al ámbito humano a través de personajes "desplazados". El héroe corredor no es sino símbolo de aquel sentimiento de no estar del todo y, por lo tanto, del sentimiento fantástico que Cortázar desarrolla en su cuentística.

La misma idea nos habla también de una descolocación territorial, de una no identificación o de una identificación parcial con un espacio geográfico y una comunidad determinados y, por consiguiente, de la condición descolocada, escindida, que parece caracterizar el devenir identitario y cultural latinoamericanos. Así, el protagonista de "El otro cielo", quien, por cierto, carece de nombre, es un sujeto que bordea la indefinición, que está a medias, que se halla dividido entre un mundo y otro (un cielo y otro). Se trata de un individuo en el que, como hemos dicho, conviven dos mundos, pero de una forma problemática, en la medida en que éstos se encuentran enfrentados, en que cada uno está construido con base en la oposición frente al otro. De este modo, y de manera similar a la mecánica de otros relatos cortazarianos ${ }^{5}$, los lazos entre los ámbitos de Buenos Aires y París se llevan a cabo por medio de dos recursos: la oposición y el paralelismo.

5 Por ejemplo, "Axolotl" y "La noche boca arriba". 
En primer lugar, se establece un paralelo histórico en el que la violencia y el terror constituyen el común denominador de ambos espacios narrativos: mientras en el mundo de París amenaza la invasión prusiana -que tomará lugar en 1870-, se hace uso de la guillotina y ha hecho aparición un temido estrangulador de prostitutas; en el mundo de Buenos Aires se ha instalado la dictadura de Perón, el ejército ha tomado el control y se viven muy de cerca las sacudidas de la Segunda Guerra Mundial: los cielos devienen infiernos.

La oposición, por su parte, se da al presentar el espacio otro, en este caso París, como un signo invertido con respecto al espacio formulado en primer lugar, Buenos Aires. Aquí nuestro héroe es un honrado trabajador de la Bolsa, hijo único y novio formal. En Francia lleva una existencia bohemia, se convierte en amante de una prostituta de nombre Josiane y frecuenta cafés de mala reputación. París representa "ese mundo que ha optado por un cielo más próximo, de vidrios sucios..." (591), "ese mundo diferente donde no había que pensar en Irma y se podía vivir sin horarios fijos, al azar de los encuentros y de la suerte" (596). Éste es el cielo de lo corrupto y de lo perverso, el cielo del Mal, donde el personaje experimenta una vida erótica liberada, donde privan los instintos. La oposición complementaria París/Buenos Aires es verdaderamente crucial para entender el proceso identitario latinoamericano en general y rioplatense en particular, a partir del siglo XIX. Por eso no es extraño que, además de que el personaje viva otro tiempo, otro espacio y otra personalidad al cruzar la zona de las galerías cubiertas, posea en ese mundo inverso, un alter ego un 'otro yo' al que se conoce como "el sudamericano".

Los personajes femeninos también muestran esta contraposición: a un lado, la madre abnegada y preocupada y la correctísima novia de clase media a la espera del matrimonio: "Para ella, como para mi madre, no hay mejor actividad social que el sofá de la sala donde ocurre eso que llaman la conversación, el café y el anisado" (591). Al otro, las desinhibidas prostitutas de las calles y los bares, entre las que se halla la amante, quien no pregunta por sus ausencias, con la que, en definitiva, nada está previsto. Nuevamente ambos ámbitos enfrentados se constituyen en anverso y reverso, en doble opuesto en el que cada costado requiere del otro para ser, para alcanzar sentido. Es precisamente la operación de contraste la que enfatiza el carácter represivo, hipócrita, bañado de buenas costumbres (de la "Gran Costumbre") de uno de los mundos y, por el contrario, el liberado, el aparentemente auténtico del otro de ellos. Notemos que París encarna la dimensión del instinto que va frecuentemente asociada a un tiempo pasado, a unos orígenes dejados atrás. Por otra parte, vemos cómo se produce en el relato una constante escisión de la trama en estructuras opuestas, ya sea pertenecientes a la conciencia del protagonista, ya a la(s) geografía(s) o a la(s) época(s) en que se desarrolla el relato.

Los textos que introducen las dos unidades o segmentos mediante las que se organiza el cuento focalizan el tema de la identidad del protagonista y lo vinculan con la voz del narrador. Dichos pasajes corresponden a citas de Les chants de Maldoror, largo poema narrativo que publicó en 1868 y en París el escritor uruguayo Isidore Ducasse, bajo el seudónimo de Conde de Lautréamont. El primero de los epígrafes se refiere precisamente al desdoblamiento del escritor en un personaje maligno. Alude al momento en que Maldoror comprueba aterrado que el fantasma que lo ha hechizado es una reflexión especular de sí mismo, que son sus propios ojos los del brillo infernal. El segundo 
retrata el barrio de las galerías cubiertas en el que vivió Ducasse los últimos meses de su breve existencia. Recordemos además que los Cantos fueron considerados escandalosos, satánicos y motivo de persecución para el poeta. Asimismo, ya ha señalado la crítica ${ }^{6}$ la relación entre Laurent, el estrangulador, y Ducasse: el nombre de Laurent parece ser una abreviatura de Lau(t)re(eamo)nt y, en ese sentido, una parte de éste. De modo tal que el sudamericano en su hopalanda negra deviene símbolo tanto del escritor uruguayo real como del asesino (Laurent) del relato. Ambos fungen así como alter egos del narrador, como representantes de su lado oscuro, pecaminoso, del lado puramente instintivo. Perfil que, a la vez, parece ser el más deseado por el protagonista, con el cual se siente más identificado. Recuérdese que se refiere a esa dimensión oscura, figurada espacialmente en la ciudad de París como "nuestro reino", "nuestro café", "nuestro mundo".

"El otro cielo" constituye, pues, un modelo palpable de la forma como el yo se desplaza entre lo que le han dicho que sea y lo que él quiere ser; polos ciertamente difusos, en los que ese yo se reconoce o desconoce, se identifica y aliena por igual. De hecho, el protagonista termina identificándose tanto con el marido apacible que se ve obligado a ser como con el escritor maldito al que aspiraba acercarse. Es justamente esa tensión entre el deber-ser y el querer-ser, entre lo que nos han dicho que somos y lo que queremos o soñamos ser la que expresa una cierta imagen -determinada histórica, ideológica y culturalmente- del latinoamericano, tal como lo leemos a través de Cortázar. Es en ambos extremos que el sujeto de América Latina se reconoce, puesto que -y aquí se asoma una vez más la conflictiva relación con lo otro que parece caracterizarnos- lo que se desea ser tampoco es completamente ajeno, sino de algún modo parte de lo que ya se es: el discurso ajeno colonizador ha permeado también las propias proyecciones. De ahí que lo propio y lo otro se confundan, se entremezclen y se contradigan en un proceso sin término. ¿Y qué es finalmente lo propio y lo ajeno, sino dos momentos de un mismo devenir? Así, el protagonista de "El otro cielo" y el Maldoror de Ducasse se identifican, se ven reflejados como lo otro, ven en sí mismos lo opuesto, ven en el Bien el Mal, en el buen ciudadano argentino el vividor parisino, en el bucólico y convencional Buenos Aires el París bohemio y trasnochado, y viceversa. De este modo se perciben porque, a fin de cuentas, están conformados por esa dualidad antitética.

Ahora bien, la convivencia entre tales esferas contrapuestas es tan problemática que nunca llega a resolverse; algo ocurre siempre que rompe la conexión entre ellas, que o destruye al protagonista o lo retiene en uno de los lados en cuestión. La fusión, la totalidad, la integración de los opuestos jamás llega a cumplirse verdaderamente. En cierto momento, como una forma de aproximación, el protagonista siente "que debió decirle algunas frases en español" al "sudamericano", y el no haberlo hecho lo llena de un sentimiento de culpa: "creo que hice mal, que estuve al borde de un acto que hubiera podido salvarme" (598). Tal vez, ese pequeño gesto comunicativo hubiera permitido mantenerlo en contacto con su reverso. Sin embargo, desde que ocurren las simétricas

6 Véase: Rodríguez, "Le fantôme". 
muertes del mismo "sudamericano" y de Laurent (el otro alter ego), el narrador ya no puede transitar hacia el otro cielo, porque de alguna manera también él ha muerto: "Algunos días me da por pensar en el sudamericano, y en esa rumia desganada llego a inventar como un consuelo, como si él nos hubiera matado a Laurent y a mí con su propia muerte" (606). En esos momentos empieza "a sentir que el barrio de las galerías ya no era como antes el término de un deseo, [...] a admitir desde muy lejos que no era ya el puerto de reposo [...]" (603), y le va "invadiendo algo que era como un abandono, el sentimiento indefinible de que eso no hubiera debido ocurrir de esa forma, que algo estaba amenazando en mí el mundo de las galerías y los pasajes [..., que] de alguna manera eso era un término [...]" (601). Por último, sentencia: "Nunca he querido admitir que la guirnalda estuviera definitivamente cerrada y que no volvería a encontrarme con Josiane en los pasajes o bulevares" (606). Aunque el horizonte brinde la ilusión de que Buenos Aires y París están intrincados, la verdad es que no logran otra comunicación más que la fantasiosa de las galerías en "El otro cielo".

El texto deja leer de este modo la constitución de un sujeto-protagonista móvil cuyo lugar no está dentro de ningún espacio-mundo en particular, sino en los intersticios de ellos, en el tránsito, no pudiendo asimilar de forma definida los mundos en los que se desplaza, sino, más bien, constituyéndose en ese desplazamiento. Desde ese punto de vista, dicho personaje se configura en sujeto transcultural, que pone en escena una noción de identidad esquiva, en constante movimiento y en continuo cuestionamiento (quién se es, quién se quiere y quién se debe ser)

A modo de conclusión, podemos puntualizar:

1. "Lejana" y "El otro cielo" revelan, desde de sus específicas configuraciones literarias, la añoranza de un centro, de una totalidad armoniosa, la que, a su vez, descubre la visión de un sujeto y una realidad desintegrados, desajustados y heterogéneos, así como un sentimiento de incertidumbre existencial e identitaria.

2. Dichas representaciones de subjetividad escindida y de realidad fragmentada no solo pueden ser leídas desde una perspectiva universal que considere a los textos como expresión del ser humano contemporáneo alienado, sino también, complementariamente, desde el contexto latinoamericano, como expresión de una realidad individual y colectiva enajenada, fragmentada y plural, y en ese sentido, como manifestación de una identidad latinoamericana problematizada por esos condicionamientos. Esa manifestación identitaria puede entenderse, ciertamente, a partir de las palabras con que el propio Cortázar explica su visión y posición en el mundo como "Una coexistencia pocas veces pacífica de por lo menos dos aperturas al mundo [...], una yuxtaposición [...que] se manifiesta en el sentimiento de no estar del todo en cualquiera de las estructuras, de las telas que arma la vida y en la que somos a la vez araña y mosca" (Cortázar, El sentimiento 32).

3. El choque de realidades heterogéneas que provoca la irrupción de lo fantástico, posibilita la revelación de la otredad. Así se configuran personajes problemáticos, constituidos en el tránsito entre dos mundos antagónicos, imposibles de conciliar. Esos personajes pueden 
ser interpretados bajo la categoría de sujetos transculturales y, por ende, heterogéneos, y, en consecuencia, como una expresión de la ambigüedad identitaria de la cultura del Río de la Plata. De manera que la cuestión de la identidad rioplatense vendría a expresarse en estos cuentos, primordialmente, como una problemática ontológica e individual, como profundos conflictos del yo consigo mismo, reveladores de su inseguridad existencial. Pero, evidentemente, esas manifestaciones dejan leer una historia que trasciende las fronteras del ego e ilumina problemáticas culturales mucho más amplias.

4. Esa paradójica relación con lo otro que patentiza la poética de Cortázar -su visión del ser humano como esponja fenoménica, "siempre lleno de todo aquello que no es"-, y que encarnan significativamente sus personajes, permite, en efecto, leer sus textos como una gran metáfora de la identidad latinoamericana, entendida ésta como expresión de esa "heterogeneidad no dialéctica" advertida por Cornejo Polar. Ciertamente, tal manifestación identitaria continental parece caracterizarse, precisamente, y entre otras cosas, por la inclusión histórica (y conflictiva) del discurso ajeno, de la mirada del otro, en el decir propio; o sea, por la convivencia problemática, muchas veces contradictoria e incongruente de múltiples puntos vista. Tal identidad esquiva, confusa, nunca plenamente integrada, se presenta como el correlato de una cultura leída desde un imaginario foráneo, fundada como una idea de Europa, por tanto, históricamente escindida, enajenada. En efecto, aquello que particularmente leemos como fracaso de conciliación, presente en la mayoría de los cuentos de Cortázar (como también en su paradigmática novela Rayuela) encarna asimismo, simbólicamente, la problemática cultural de los países latinoamericanos, en la medida en que evidencia la imposibilidad de la unidad (aunque sea en la diversidad) y enfatiza el conflicto de las alteridades, de una identidad "heterogénea no dialéctica", en la cual la síntesis finalmente no tiene lugar. En este sentido, los textos seleccionados y muchos otros no solo dejan al descubierto la innegable otredad que constituye al género humano (el yo no puede llegar a ser sí mismo sin el otro), sino que expresan la honda pugna con esa otredad que conforma históricamente al hombre y a la mujer de América Latina, así como el fracaso del proyecto de asimilación, de integración tantas veces planteado.

5. En suma, la escritura de Julio Cortázar -al menos una parte de ella- con sus dobles y sus pasajes deviene metáfora dolorosa -aunque a veces también irónica- de lo inconciliable. Las continuas búsquedas y saltos no llevan a ninguna armoniosa totalidad o centro estable; al revés, revelan la constitución de un sujeto y una realidad plurales, escindidos y en conflicto. En ese tenor, ellas bien pueden interpretarse como imágenes de la condición histórica latinoamericana, cuya razón legitimadora no es ni la síntesis conciliante, ni un mestizaje que supone una unidad más o menos desproblematizada (y que, claro, se conforma en el espacio de la cultura hegemónica); sino, al contrario, las hondas desintegraciones y tensiones identitarias, expresadas con frecuencia en nuestra literatura -igualmente heteróclita y conflictiva-a través de la construcción de discursos discontinuos, fragmentados, contradictorios, en fin, heterogéneos. 


\section{BIBLIOGRAFÍA}

Arpini, Adriana. "El latinoamericanismo de los argentinos". La Argentina del 80'al 80'. Balance social y cultural de un siglo. Comp. Arturo Roig. México: UNAM, 1993. 209-240.

Bajtin, Mijaíl. Problemas de la poética de Dostoievsky. México: FCE, 2003. Estética de la creación verbal. México: Siglo XXI, 2003.

Cornejo Polar, Antonio. "El problema nacional en la literatura peruana". Sobre literatura y crítica latinoamericanas. Caracas: UCV, 1982. 19-31.

"Una heterogeneidad no dialéctica: sujeto y discurso migrantes en el Perú moderno". Revista Iberoamericana. LXII / 176-177 (1996): 837-844.

Escribir en el aire. Ensayo sobre la heterogeneidad sociocultural en las literaturas andinas. Lima: Editorial Horizonte, 1994.

Cortázar, Julio. “Lejana”. 1951. Cortázar Cuentos Completos / 1. México: Alfaguara, 1996. 119-125. 590-606.

"El otro cielo". 1966. Cortázar Cuentos Completos / 1. México: Alfaguara, 1996.

"El sentimiento de no estar del todo". La vuelta al día en ochenta mundos. Tomo I. 1967. México: Siglo XXI, 2002.

Donni de Mirande, Nelly. "Notas sobre la lengua de Cortázar". Boletín de Literaturas hispánicas 6 (1966): 71-83.

Richards, Nelly. "Intersectando Latinoamérica con el latinoamericanismo: saberes académicos, práctica teórica y crítica cultural”. Revista Iberoamericana LXIII / 180 (1997): 345-361.

Rodríguez Monegal, Emir. "Le fantôme de Lautréamont”. Revista Iberoamericana 84-85 (julio-diciembre 1973): 625-639.

Rodríguez Ozán, María Elena. "Latinoamérica en la conciencia argentina”. Latinoamérica, Cuadernos de Cultura Latinoamericana. 37 (1979): 6.

Palabras Clave: Cortázar, identidad latinoamericana, heterogeneidad contradictoria, Cornejo Polar, cuento fantástico.

KEY WORDS: Cortázar, Latin-American identity, heterogeneity, Cornejo Polar, fantastic tale. 